\title{
Ultrafiltration Failure in Peritoneal Dialysis: A Pathophysiologic Approach
}

\author{
Isaac Teitelbaum \\ University of Colorado School of Medicine, Aurora, Colo., USA
}

\author{
Key Words \\ Ultrafiltration failure - Peritoneal dialysis - Rapid transport . \\ Aquaporin · Encapsulating peritoneal sclerosis · Lymphatics
}

Key Messages: Knowledge of the specific pathophysiology of the various causes of ultrafiltration failure will aid in the diagnosis thereof.

\begin{abstract}
Background: Ultrafiltration failure is a significant cause of technique failure for peritoneal dialysis and subsequent transfer to hemodialysis. Summary: Ultrafiltration failure is defined as failure to achieve at least $400 \mathrm{ml}$ of net ultrafiltration during a $4 \mathrm{~h}$ dwell using $4.25 \%$ dextrose. Four major causes of ultrafiltration failure have been described. A highly effective peritoneal surface area is characterized by transition to a very rapid transport state with D/P creatinine $>0.81$. Low osmotic conductance to glucose is characterized by attenuation of sodium sieving and decreased peritoneal free water clearance to $<26 \%$ of total ultrafiltration in the first hour of a dwell. Low effective peritoneal surface area manifests with decreases in the transport of both solute and water. A high total peritoneal fluid loss rate is the most difficult to diagnose clinically; failure to achieve ultrafiltration with an 8-10 h icodextrin dwell may provide a clue to diagnosis.
\end{abstract}

\section{Introduction}

Peritoneal dialysis needs to provide patients with both solute clearance and fluid removal, that is, ultrafiltration. Failure to provide adequate levels of either or both of these parameters accounts for approximately $18 \%$ of overall technique failure and transfer to hemodialysis [1]. Ultrafiltration failure will manifest itself by the clinical findings of volume overload. It is important to recognize, however, that not all patients with clinical findings of volume overload will have true ultrafiltration failure; one must first rule out noncompliance with diet or the dialysis regimen, defects of the abdominal cavity boundary leading to fluid sequestration, and uncompensated loss of residual kidney function as possible causes of volume overload. True ultrafiltration failure is defined by 'the rule of fours': failure

\section{KARGER 125}

(c) 2015 S. Karger AG, Base

$0253-5068 / 15 / 0393-0070 \$ 39.50 / 0$

E-Mail karger@karger.com

www.karger.com/bpu
Isaac Teitelbaum, MD, FACP, Professor of Medicine

Director, Acute and Home Dialysis Programs

University of Colorado Hospital, AIP

12605 E. 16th Avenue, Box F774, Aurora, CO 80045 (USA)

E-Mail isaac.teitelbaum@ucdenver.edu 
to achieve at least $400 \mathrm{ml}$ of net ultrafiltration during a $4 \mathrm{~h}$ dwell using $4.25 \%$ dextrose. Four types of ultrafiltration failure have been described, previously referred to simply as types 1 through 4 . It is now recognized that each type of ultrafiltration failure has distinct pathophysiologic features; this will form the subject of this review.

\section{High Effective Peritoneal Surface Area (Type 1)}

This most common form of ultrafiltration failure arises as a consequence of changes in the peritoneal membrane over time causing a transition to a very rapid transport status. This results in the rapid dissipation of the osmotic gradient and consequently poor ultrafiltration. The reader is referred to the excellent review by Fussholer [2] for a detailed description of these changes. In brief, the uremic state itself, prolonged exposure to glucose and its degradation products (GDPs), and the cumulative effects of episodes of peritonitis result in the production of various proinflammatory and angiogenic mediators. These include various cytokines, endothelial nitric oxide synthase (eNOS), and growth factors such as transforming growth factor beta (TGF $\beta$ ) and vascular endothelial growth factor (VEGF). These, in turn, are associated with neo-angiogenesis with leaky capillaries, culminating in increased effective peritoneal surface area and rapid solute transport with diminished ultrafiltration capacity. Clinically, the hallmark of this disorder is the new finding of a $\mathrm{D} / \mathrm{P}$ creatinine ratio $>0.81$.

Once established, treatment of this form of ultrafiltration failure is very difficult, with only one maneuver having been shown to be effective. Peritoneal resting - cessation of peritoneal dialysis for a period of 4 weeks - has been shown to result in significant decreases in the mass transfer coefficients for urea and creatinine as well as a significant increase - almost double increase - in ultrafiltration capacity. The increase in ultrafiltration capacity is sustained for at least a year thereafter [3].

Several interventions have been suggested to lessen the likelihood of progression to a more rapid transport state over time. Davies et al. demonstrated that whereas the exclusive use of glucose-based fluids was associated with a progressive increase in $\mathrm{D} / \mathrm{P}$ creatinine and decreased ultrafiltration capacity over a period of two years, patients who used a single daily exchange of icodextrin exhibited no change in $\mathrm{D} / \mathrm{P}$ creatinine and no loss of ultrafiltration capacity [4]. Blockade of the renin-angiotensin-aldosterone system has been shown to have salutary effects as well. Kolesnyk et al. demonstrated that the use of an an- giotensin converting enzyme inhibitor or angiotensin receptor blocker was associated with a significant diminution in the magnitude of the increase in solute transport over a period of four years [5]. It has been suggested that the use of neutral $\mathrm{pH}$ low GDP fluids may be beneficial as well but the evidence to date is inconclusive $[6,7]$.

\section{Low Osmotic Conductance to Glucose (Type 2)}

The transcapillary movement of free water via aquaporin 1 accounts for 40 to $50 \%$ of total ultrafiltration across the peritoneal membrane $[8,9]$. In the second type of ultrafiltration failure, decreased osmotic conductance in response to glucose leads to inadequate water removal via aquaporins. The clinical hallmark of this form of ultrafiltration failure is attenuation of sodium sieving, that is, dampening of the decrease in dialysate sodium during the first hour of a dwell with $3.86 \%$ glucose [10]. Free water transport via aquaporins can be estimated clinically by first assessing ultrafiltration via the small pore over a period of one hour and subtracting this from the total ultrafiltration over the same period; free water transport $\leq 26 \%$ of total ultrafiltration is consistent with impaired aquaporin function [9].

As demonstrated by Goffin et al. this condition appears to be due to a functional alteration of the aquaporins rather than a quantitative decrease in their number [11]. The cause of the functional alteration in aquaporins is yet to be elucidated; there is much speculation on the roles of glycosylation or endothelial nitric oxide. Previous studies in the rat have shown that peritoneal expression of aquaporin 1 can be up-regulated by high dose corticosteroids [12]. The same appears to be true in man as well; in three patients with deficient aquaporin function who subsequently underwent kidney transplantation, it was demonstrated that the use of high dose steroids in the immediate post-transplant period was associated with increased free water transport across the peritoneum and increased sodium sieving [13]. However, one obviously cannot advocate the long-term use of systemic corticosteroids solely to augment aquaporin function in otherwise healthy PD patients; another strategy is clearly needed.

The groundwork for one such potential strategy has recently been laid by the elegant work of Devuyst and colleagues [14]. Using a furosemide scaffold, these investigators have developed an agonist of aquaporin 1 that potentiates the activity of the water channel in vitro and, when used in vivo in a mouse model of peritoneal dialysis, enhances the osmotic transport of water across the peritoneal membrane and augments sodium sieving. While 
much work is yet to be done to determine the safety and efficacy of this approach in man, this is a very exciting development with the potential to offer a therapeutic approach for this form of ultrafiltration failure.

\section{Low Effective Peritoneal Surface Area (Type 3)}

In this rare form of ultrafiltration failure, diffuse hypopermeability of the peritoneal membrane results in impairment of both solute transport and ultrafiltration [2]. Clinically, these patients may therefore present with signs of volume overload, symptoms of inadequate solute removal, or both. The diffuse hypopermeability of the peritoneal membrane appears to be caused by the effects of pro-fibrotic mediators such as TGF $\beta$ and as a consequence of epithelial to mesenchymal transition which results in mesothelial denudation, submesothelial fibrosis, and obliterating vasculopathy $[2,15]$. When the severity levels are moderate, this may result in simple sclerosis of the peritoneal membrane with diminution in transport but without more serious clinical consequences. In its more severe form, however, this may culminate in the most extreme complication of peritoneal dialysis, encapsulating peritoneal sclerosis (EPS). EPS is a clinical syndrome characterized by bowel obstruction - intermittent, recurrent, or persistent - caused by a wide range of adhesions of a diffusely hypertrophied and often calcified peritoneum [16]. The frequency of EPS increases with the duration of peritoneal dialysis; patients on PD for $>8$ years are at higher risk [17]. EPS has been exhaustively reviewed elsewhere [16-18] and extensive discussion thereof is beyond the scope of this article; I shall confine myself to a brief discussion of therapy.

While it is generally accepted that PD should be discontinued in patients with EPS, there is some question regarding the utility of continuing intermittent peritoneal lavage. Studies have suggested that doing so may aid in the removal of noxious mediators such as matrix metalloproteinases that have been implicated in the pathogenesis of EPS [19]. The observation that some cases of EPS arise after cessation of PD (e.g., after kidney transplantation) has also bolstered the notion that continued peritoneal lavage may be beneficial.

Until very recently, medical therapy of EPS has centered on the use of immunosuppressive agents: corticosteroids, azathioprine, mycophenalate, sirolimus, and everolimus have all been tried with limited success [20-22]. More recently, the use of tamoxifen has been reported to be beneficial in the treatment of EPS. In a small study from England, the addition of tamoxifen was reported to result in an increase in median survival from 12 to 21 months compared to the use of immunosuppression alone [20]. In a larger study from the Netherlands, the outcome of 24 patients treated with tamoxifen was compared to that of 39 patients treated with immunosuppression alone [21]. Despite similar demographic and clinical characteristics, mortality was significantly decreased from $74.4 \%$ in the group treated with immunosuppression alone to $45.8 \%$ $(\mathrm{p}=0.03)$ in the group treated with tamoxifen as well.

In severe cases of EPS, surgical enterolysis may be necessary. This is a difficult procedure with a high risk for bowel perforation and it is associated with a significant risk of mortality. When undertaken, this surgery should be performed in a center with significant experience with EPS [23]. Nutritional support of patients with EPS is a key component of therapy as well.

\section{High Total Peritoneal Fluid Loss Rate (Type 4)}

This form of ultrafiltration failure is due to an increase in the rate of bulk fluid absorption from the peritoneal cavity into lymphatics and into the local tissues. This condition was previously referred to as high 'effective lymphatic absorption rate' [2] but this is a misnomer as no more than $10-30 \%$ of the total fluid absorbed leaves the peritoneal cavity via the lymphatics [24]. The magnitude of fluid loss may be estimated by examining the rate of egress of radiolabeled albumin from the peritoneal cavity. This analysis is relatively difficult to perform and is not routinely available clinically. As icodextrin is removed from the peritoneal cavity via the lymphatics, and since even rapid transporters will usually achieve ultrafiltration with the use of icodextrin, it has been suggested that failure to achieve ultrafiltration with icodextrin may be construed as indirect evidence for a high rate of fluid absorption from the peritoneal cavity.

The pathogenesis of this form of ultrafiltration failure is poorly understood. A recent study in a rat model of peritoneal fibrosis suggests that TGF- $\beta 1$ may play a role in promoting lymphangiogenesis [25]. This condition is relatively rare, which is fortunate as there is little to offer therapeutically and PD must often be discontinued. The utility of bethanechol, a cholinergic agent that enhances the contraction of subdiaphragmatic lymphatic stomata thereby decreasing the lymphatic flow, was examined in a small study of 9 patients. Given orally for 5 days at a mean dose of $0.27 \mathrm{mg} / \mathrm{kg} /$ day (maximum $50 \mathrm{mg}$ ), the use of bethanechol resulted in only a modest $18.4 \%$ improvement in $4 \mathrm{~h}$ drain volume $(\mathrm{p}<0.05)$ with no change in solute transport characteristics [26].
Teitelbaum 


\section{Conclusions}

Ultrafiltration failure should be considered in patients presenting with clinical findings of volume overload in whom noncompliance with diet or the dialysis regime, defects of the abdominal cavity boundary, and uncompensated loss of kidney function have been eliminated as the possible causes. Knowledge of the specific pathophysiology of the various causes of ultrafiltration failure will aid in the diagnosis. A highly effective peritoneal surface area is associated with transition to a rapid transport state and isolated ultrafiltration failure, whereas patients with a less effective peritoneal surface area will exhibit impairment of solute transport as well as poor ultrafiltration. Low osmotic conductance to glucose is marked by the loss of sodium sieving and decreased peritoneal free water clearance. Maintenance of normal solute transport characteristics and normal sodium sieving suggests a problem with excessive bulk absorption of fluid from the peritoneal cavity; failure to achieve ultrafiltration with an 8-10 h icodextrin dwell may provide a clue to the diagnosis.

\section{References}

1 Mujais S, Story K: Peritoneal dialysis in the US: evaluation of outcomes in contemporary cohorts. Kidney Int Suppl 2006;103:S21-S26.

$\checkmark 2$ Fusshoeller A: Histomorphological and functional changes of the peritoneal membrane during long-term peritoneal dialysis. Pediatr Nephrol 2008;23:19-25.

3 de Alvaro F, Castro MJ, Dapena F, Bajo MA, Fernandez-Reyes MJ, Romero JR, Jimenez C, Miranda B, Selgas R: Peritoneal resting is beneficial in peritoneal hyperpermeability and ultrafiltration failure. Adv Perit Dial 1993;9:56-61.

-4 Davies SJ, Brown EA, Frandsen NE, Rodrigues AS, Rodriguez-Carmona A, Vychytil A, Macnamara E, Ekstrand A, Tranaeus A, Filho JC; EAPOS Group: Longitudinal membrane function in functionally anuric patients treated with APD: data from EAPOS on the effects of glucose and icodextrin prescription. Kidney Int 2005;67:1609-1615.

5 Kolesnyk I, Noordzij M, Dekker FW, Boeschoten EW, Krediet RT: A positive effect of AII inhibitors on peritoneal membrane function in long-term PD patients. Nephrol Dial Transplant 2009;24:272-277.

6 Williams JD, Topley N, Craig KJ, Mackenzie RK, Pischetsrieder M, Lage C, Passlick-Deetjen J; Euro Balance Trial Group: The Euro-Balance Trial: the effect of a new biocompatible peritoneal dialysis fluid (balance) on the peritoneal membrane. Kidney Int 2004;66:408-418.

7 Johnson DW, Brown FG, Clarke M, Boudville N, Elias TJ, Foo MW, Jones B, Kulkarni H, Langham R, Ranganathan D, Schollum J, Suranyi MG, Tan SH, Voss D; balANZ Trial Investigators: The effect of low glucose degradation product, neutral $\mathrm{pH}$ versus standard peritoneal dialysis solutions on peritoneal membrane function: the balANZ trial. Nephrol Dial Transplant 2012;27:4445-4453.

8 Yang B, Folkesson HG, Yang J, Matthay MA, Ma T, Verkman AS: Reduced osmotic water permeability of the peritoneal barrier in aquaporin-1 knockout mice. Am J Physiol 1999; 276:C76-C81.

-9 La Milia V, Di Filippo S, Crepaldi M, Del Vecchio L, Dell'Oro C, Andrulli S, Locatelli F:
Mini-peritoneal equilibration test: a simple and fast method to assess free water and small solute transport across the peritoneal membrane. Kidney Int 2005;68:840-846.

10 Ho-dac-Pannekeet MM, Krediet RT: Water channels in the peritoneum. Perit Dial Int 1996;16:255-259.

11 Goffin E, Combet S, Jamar F, Cosyns JP, Devuyst O: Expression of aquaporin-1 in a long-term peritoneal dialysis patient with impaired transcellular water transport. Am J Kidney Dis 1999;33:383-388.

12 Stoenoiu MS, Ni J, Verkaeren C, Debaix H, Jonas JC, Lameire N, Verbavatz JM, Devuyst $\mathrm{O}$ : Corticosteroids induce expression of aquaporin-1 and increase transcellular water transport in rat peritoneum. J Am Soc Nephrol 2003;14:555-565.

$>13$ de Arteaga J, Ledesma F, Garay G, Chiurchiu C, de la Fuente J, Douthat W, Massari P, Terryn S, Devuyst O: High-dose steroid treatment increases free water transport in peritoneal dialysis patients. Nephrol Dial Transplant 2011;26:4142-4145.

$\checkmark 14$ Yool AJ, Morelle J, Cnops Y, Verbavatz JM, Campbell EM, Beckett EA, Booker GW, Flynn G, Devuyst O: AqF026 is a pharmacologic agonist of the water channel aquaporin-1. J Am Soc Nephrol 2013;24:1045-1052.

-15 Aroeira LS, Aguilera A, Sanchez-Tomero JA, Bajo MA, del Peso G, Jimenez-Heffernan JA, Selgas R, Lopez-Cabrera M: Epithelial to mesenchymal transition and peritoneal membrane failure in peritoneal dialysis patients: pathologic significance and potential therapeutic interventions. J Am Soc Nephrol 2007; 18:2004-2013.

16 Kawaguchi Y, Kawanishi H, Mujais S, Topley N, Oreopoulos DG: Encapsulating peritoneal sclerosis: definition, etiology, diagnosis, and treatment. International Society for Peritoneal Dialysis Ad Hoc Committee on Ultrafiltration Management in Peritoneal Dialysis. Perit Dial Int 2000;20:S43-S55.

17 Kawanishi H, Kawaguchi Y, Fukui H, Hara S, Imada A, Kubo H, Kin M, Nakamoto M, Ohira $\mathrm{S}$, Shoji T: Encapsulating peritoneal sclerosis in
Japan: a prospective, controlled, multicenter study. Am J Kidney Dis 2004;44:729-737.

18 Braun N, Alscher MD, Kimmel M, Amann K, Büttner M: Encapsulating peritoneal sclerosis an overview. Nephrol Ther 2011;7:162-171.

19 Hirahara I, Inoue M, Okuda K, Ando Y, Muto S, Kusano E: The potential of matrix metalloproteinase-2 as a marker of peritoneal injury, increased solute transport, or progression to encapsulating peritoneal sclerosis during peritoneal dialysis - a multicentre study in Japan. Nephrol Dial Transplant 2007;22:560-567.

20 Balasubramaniam G, Brown EA, Davenport A, Cairns H, Cooper B, Fan SL, Farrington K, Gallagher H, Harnett P, Krausze S, Steddon S: The Pan-Thames EPS study: treatment and outcomes of encapsulating peritoneal sclerosis. Nephrol Dial Transplant 2009;24:3209-3215.

21 Korte MR, Fieren MW, Sampimon DE, Lingsma HF, Weimar W, Betjes MG: Tamoxifen is associated with lower mortality of encapsulating peritoneal sclerosis: results of the Dutch Multicentre EPS Study. Nephrol Dial Transplant 2011;26:691-697.

22 Huddam B, Azak A, Koçak G, Basaran M, Voyvoda N, Duranay M: Additive effectiveness of everolimus plus tamoxifen therapy in treatment of encapsulating peritoneal sclerosis. Ren Fail 2012;34:387-389.

23 Kawanishi H, Ide K, Yamashita M, Shimomura M, Moriishi M, Tsuchiya S, Dohi K: Surgical techniques for prevention of recurrence after total enterolysis in encapsulating peritoneal sclerosis. Adv Perit Dial 2008;24:51-55.

24 Flessner MF: Peritoneal ultrafiltration: mechanisms and measures. Contrib Nephrol 2006; 150:28-36.

25 Kinashi H, Ito Y, Mizuno M, SuZuki Y, Terabayashi T, Nagura F, Hattori R, Matsukawa Y, Mizuno T, Noda Y, Nishimura H, Nishio R, Maruyama S, Imai E, Matsuo S, Takei Y: TGF- $\beta 1$ promotes lymphangiogenesis during peritoneal fibrosis. J Am Soc Nephrol 2013;24:1627-1642.

26 Baranowska-Daca E, Torneli J, Popovich RP, Moncrief JW: Use of bethanechol chloride to increase available ultrafiltration in CAPD. Adv Perit Dial 1995;11:69-72. 